\title{
Refractory Synovial Sarcoma
}

National Cancer Institute

\section{Source}

National Cancer Institute. Refractory Synovial Sarcoma. NCI Thesaurus. Code C148296.

Synovial sarcoma that does not respond to treatment. 